Wolfgang G. Mouton MS MD FMH, * John Pfitzner FrCA, $\dagger$

Justin R. Bessell MD FRACS, *

Guy J. Maddern MS PhD FRACS*

\title{
Bronchial anatomy and single-lung ventilation in the pig
}

Purpose: To explore why two pigs died in the course of a study in which a double-lumen tube (DLT) was used to achieve single-lung ventilation, the bronchial anatomy of all six pigs involved in the study was examined at autopsy.

Methods: Autopsy involved examination of the lungs in situ and subsequent dissection of the lung tissue from the lobular bronchi.

Results: All six pigs were found to have an apical lobe (or lobular) bronchus arising from the trachea. In three it was on the right, as is usual in pigs, and in three, including the two that died, it was on the left. The mainstem bronchi to both lungs were short in all pigs, with major segmental bronchi arising just distal to the carina.

Conclusion: The bronchial anatomy of the pig is such that the inflated cuffs of commercially available DLTs may cause partial or complete obstruction of the apical bronchi of one or both lungs, regardless of the side of the tracheal bronchus. The transmission of the resulting breath sounds across the narrow pig thorax can make auscultation unhelpful in assisting with optimal tube placement.

Objectif : Afin de déterminer la cause du décès de deux porcs au cours d'une étude pendant laquelle on a utilisé un tube double lumière (TDL) pour réaliser la ventilation unipulmonaire, on a procédé à l'autopsie de l'anatomie bronchique des six porcs de l'étude.

Méthode : L'autopsie comprenait l'examen des poumons in situ suivi d'une dissection du tissu pulmonaire des bronches lobulaires.

Résultats : On a trouvé chez les six porcs une bronche apicale lobulaire issue de la trachée. À droite chez trois porcs et à gauche chez les autres, incluant les deux animaux décédés pendant l'étude. Les troncs bronchiques des deux poumons étaient courts chez tous les porcs et les bronches segmentaires principales prenaient naissance près de la carène.

Conclusion : L'anatomie bronchique du porc est telle que les ballonnets gonflés des TDL commercialement offerts peuvent causer une obstruction partielle ou complète des bronches apicales d'un ou des deux poumons, peu importe de quel côté se trouve la bronche trachéale. La transmission du murmure vésiculaire qui suit peut rendre l'auscultation de l'étroit thorax du porc inutile dans la tentative d'une mise en place optimale du tube.

From the Departments of Surgery* and Anaesthesia, $\uparrow$ The Queen Elizabeth Hospital, University of Adelaide, Woodville / Adelaide, South Australia 5011 Australia.

Address correspondence to: Dr. John Pfitzner, Department of Anaesthesia, The Queen Elizabeth Hospital, Woodville, South Australia 5011, Australia. Phone: + 61-8-8222-6000; Fax: + 61-8-8222-7065; E-mail: jpfitzner@tqehsmtp.tqch.sa.gov.au Accepted for publication March 31, 1999 
$\mathrm{R}$ EPORTS of studies in pigs that involve single-lung ventilation, ${ }^{1-3}$ have not identified difficulties associated with the use of a double-lumen tube (DLT). In these studies the DLT was positioned either using conventional clinical criteria, ${ }^{1}$ or with the aid of a fibreoptic bronchoscope (FOB). ${ }^{2,3}$

The present paper addresses previously unreported problems that were experienced when using conventional clinical criteria to position a DLT in three pigs, two of which died in the course of one-lung anesthesia.

\section{Methods}

Material

Six pigs weighing between $31 \mathrm{~kg}$ and $34 \mathrm{~kg}$ were included in a separate ethically approved study. ${ }^{4}$ Three were administered one-lung anesthesia via a \#28 Fr left-

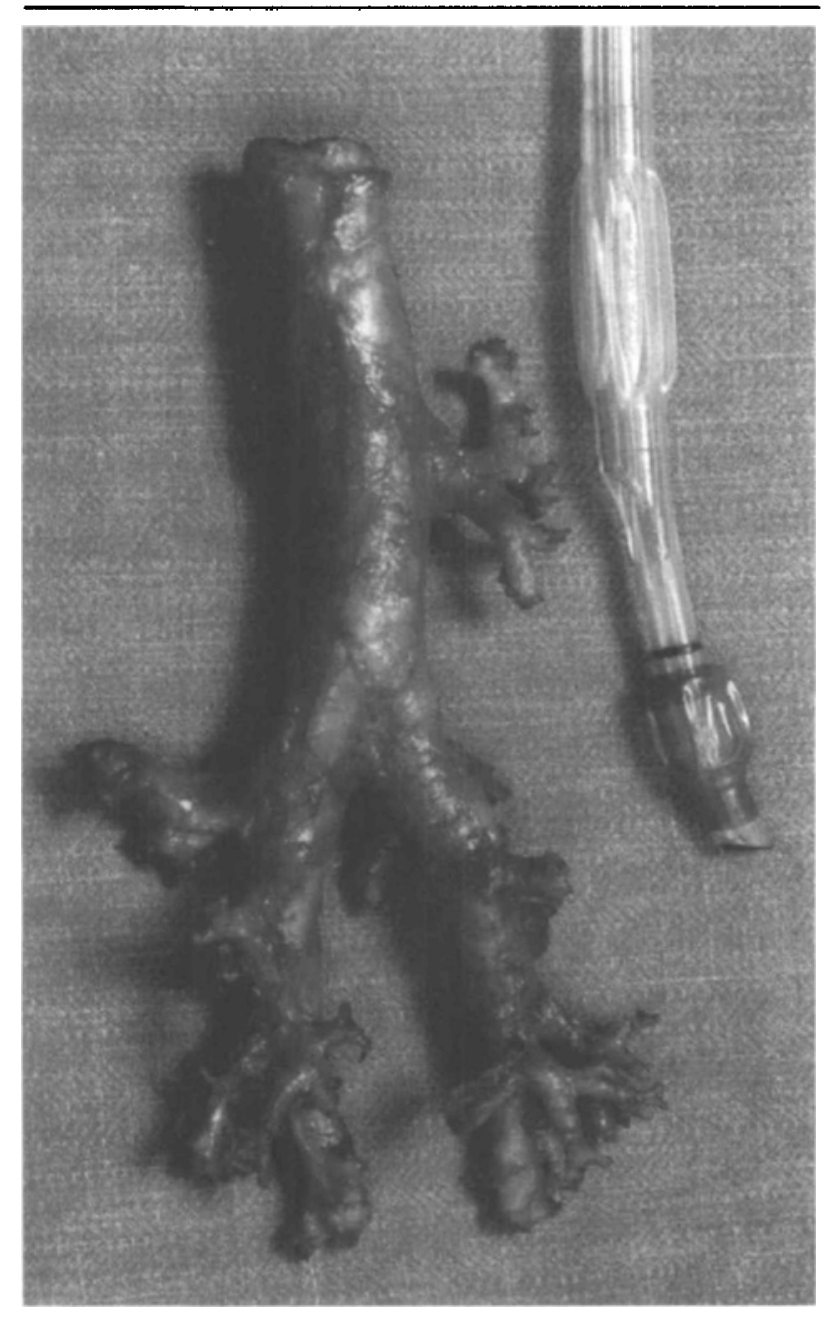

FIGURE Dissected tracheo-bronchial tree of a pig with a left tracheal bronchus, together with the left-sided DLT that was used to ventilate the left lung. sided DLT (Mallinckrodt Medical Inc.). The trachea was intubated under direct vision using a long straightbladed laryngoscope and with the tube held straight by a wire 'introducer'. After removal of the 'introducer', the DLT had to be advanced well beyond its full length, necessitating the use of $7.0 \mathrm{~cm}$ long extensions to both lumens. In the absence of a pediatric FOB, optimal DLT placement was determined by hand-ventilating each lung separately and in turn while monitoring chest movement, inflation pressures and inspiratory and expiratory flow. Although auscultation of the chest was performed to assess whether or not the apical zones were being ventilated, it was not found to be helpful since harsh breath sounds could be heard transmitted over both ventral aspects of the narrow pig upper thorax.

Anesthesia and monitoring are reported separately. ${ }^{4}$ Two of the animals died after 80 and $120 \mathrm{~min}$ of singlelung ventilation, one having survived three hours of one-lung anesthesia on a previous occasion. Pulse oximetry was being recorded from a finger-probe placed on the pig's tail and intra-arterial blood pressure was not being monitored. "Low signal" problems with the pulse oximeter appeared prior to a decrease in $\mathrm{P}_{\mathrm{ET}} \mathrm{CO}_{2}$ that was followed soon after by cardiac arrest, presumably a consequence of a critical reduction in cardiac output and acute hypoxia prior to the terminal event. The other four animals were killed at the completion of the approved study with an overdose of pentobarbital iv.

\section{Autopsy}

After examination in situ, the lungs were removed en bloc and the lung tissue dissected away from the main and lobular bronchi.

\section{Results}

\section{Autopsy findings}

In all six animals the apical lobe (or lobular) bronchus of either the left or the right lung originated directly from the trachea. In three pigs this tracheal bronchus was on the right, and in three, including the two that died, it was on the left. The mainstem bronchi were very short in all animals, especially on the side of the tracheal bronchus. On that side, some major segmental bronchi were seen to arise just distal to the carina, as is shown in Figure.

\section{Discussion}

Problems arising from the use of a DLT in pigs have not been previously reported, although in humans the potential for impaired ventilation of both upper zones has been described in a patient with a right tracheal bronchus. $^{5}$ 
Pigs have a tracheal bronchus and, relative to humans, very short mainstem bronchi. ${ }^{6}$ To match the bronchial anatomy of a given breed and size of pig with the most suitable commercially available DLT, the authors recommend that pre-study bronchoscopy and post-study autopsy be performed. A DLT with a narrow bronchial cuff may reduce the likelihood of this cuff obstructing apical segmental bronchi, while one with a long inter-cuff distance will reduce the risk of the inflated tracheal cuff obstructing the tracheal bronchus. However, a degree of bronchial obstruction may be unavoidable and, in this event, a partial obstruction, by creating a ball-valve effect and hyperinflation of the obstructed apical lobule, may cause greater physiological disturbance than would a complete obstruction.

Apical lobe obstruction, either partial or complete and on one or both sides, is likely to be responsible for the harsh breath sounds that were heard over the lung apices at auscultation. They were heard on both sides of the chest, presumably as a consequence of good sound transmission across the narrow pig 'upper' thorax. At no time could the breath sounds on either side be described as vesicular in quality.

$A$ FOB should facilitate placing the DLT in the dominant mainstem bronchus with the proximal edge of the inflated endobronchial cuff sited at or only marginally beyond the carina. Although a left tracheal bronchus may well be a rare finding in most pig populations, if it is present and if as might be expected the right mainstem bronchus appears longer than the left, it will be better to site the left-sided DLT electively in the right rather than the left mainstem bronchus.

Elective mismatching of DLT with pig bronchial anatomy might create a range of experimental models for studying the clinical and physiological effects of different DLT malplacements.

Unlike pigs and sheep, which have similar bronchial anatomy, ${ }^{7}$ humans usually have a suitably long left main bronchus and a low incidence of tracheal bronchus. A right tracheal bronchus was identified in only five patients in a series of 1,200 consecutive bilateral bronchograms, ${ }^{8}$ and in $2 \%$ of children requiring bronchoscopy for respiratory symptoms. ${ }^{9}$ When present in humans, a tracheal bronchus is sometimes referred to as a pig bronchus. ${ }^{7}$ The mirror image configuration, with not a right but a left tracheal bronchus, has not been reported in pigs, ${ }^{6}$ and is extremely rare in humans. ${ }^{10}$ Although its presence in three of six animals studied may reflect an inherited trait peculiar to the particular strain of pigs, it may well be present in other pig populations.

In conclusion, the bronchial anatomy of the pig is such that the inflated cuffs of commercially available
DLTs may cause partial or complete obstruction of the apical bronchi of one or both lungs, and auscultation of the narrow pig thorax may be unhelpful in assisting with optimal tube placement.

\section{Acknowledgments}

The authors would like to thank Mr Ken Porter and his staff in the Experimental Surgical Suite of The Queen Elizabeth Hospital for their assistance with this project.

\section{References}

1 Bessell JR, Maddern GJ, Manncke K, Ludbrook G, Jamieson GG. Combined thoracoscopic and laparoscopic oesophagectomy and oesophagogastric reconstruction. Endoscopy Surgery \& Allied Technologies 1994; 2: 32-6.

2 Hill RC, Jones DR, Vance RA, Kalantarian $B$. Selective lung ventilation during thoracoscopy: effects of insufflation on hemodynamics. Ann Thorac Surg 1996; 61: 945-8.

3 Karzai $W$, Haberstroh J, Priebe $H-J$. Effects of desflurane and propofol on arterial oxygenation during onelung ventilation in the pig. Acta Anaesthesiol Scand 1998; 42: 648-52.

4 Mouton WG, Bessell JR, Pfitzner J, Dymock RB, Brealey $J$, Maddern GJ. A randomized controlled trial to deter mine the effects of humidified carbon dioxide insufflation during thoracoscopy. Surg Endosc 1999; 13: 382-5.

5 Brodsky JB, Mark JBD. Bilateral upper lobe obstruction from a single double-lumen tube (Letter). Anesthesiology 1991; 74: 1163-4.

6 Nakakuki S. Bronchial tree, lobular division and blood vessels of the pig lung. J Med Vet Sci 1994; 56: 685-9.

7 Maesen FPV, Geraedts WH, Goei R. Agenesis of the right upper lobe. Chest 1993; 103: 1612-4.

8 Atwell SW. Major anomalies of the tracheobronchial tree. With a list of the minor anomalies. Dis Chest 1967; 52: 611-5.

9 McLaughlin FJ, Strieder DJ, Harris GBC, Vawter GP, Eraklis $A J$. Tracheal bronchus: association with respiratory morbidity in childhood. J Pediatr 1985; 106 : 751-5.

10 Remy J, Smith M, Marache P, Nuyts JP. Pathogenetic left tracheal bronchus. A review of the literature in connection with four cases. J Radiol 1977; 58: 621-30. 